\title{
Social Capital, IT Capability, and the Success of Knowledge Management Systems
}

\author{
Irene Y.L. Chen* \\ Department of Information Management, Ching Yun University, 229, \\ Chien-Hsin Rd., Jungli, 320, Taiwan, R.O.C. \\ Fax: +88634683904_E-mail: irene@cyu.edu.tw \\ *Corresponding author
}

\begin{abstract}
Many organizations have implemented knowledge management systems to support knowledge management. However, many of such systems have failed due to the lack of relationship networks and IT capability within organizations. Motivated by such concerns, this paper examines the factors that may facilitate the success of knowledge management systems. The ten constructs derived from social capital theory, resource-based view and IS success model are integrated into the current research model. Twenty-one hypotheses derived from the research model are empirically validated using a field survey of KMS users. The results suggest that social capital and organizational IT capability are important preconditions of the success of knowledge management systems. Among the posited relationships, trust, social interaction ties, IT capability do not significantly impact service quality, system quality and IT capability, respectively. Against prior expectation, service quality and knowledge quality do not significantly influence perceived KMS benefits and user satisfaction, respectively. Discussion of the results and conclusion are provided. This study then provides insights for future research avenue.
\end{abstract}

Keywords: knowledge management system success; social capital; information technology capability.

Biographical notes: Irene Y.L. Chen is an assistant professor of Department of Information Management at Ching Yun University, Jung-Li, Taiwan. She received her Ph.D. degree in MIS from National Kaohsiung First University of Science and Technology. Her research interests include Web-based learning behavior, enterprise resource planning and knowledge management. Her research findings have been published in Journal of Information Science, Computers \& Education, Educational Technology \& Society, International Journal of Human-Computer Studies, and Expert Systems with Applications.

\section{Introduction}

Knowledge management (KM) is a broad-based movement to bring together intellectual resources and make them available across organizational boundaries (Davenport \& Prusak, 1998; Robertson, 2002). Many business organizations have launched KM projects to leverage the power of knowledge assets. Implementing the knowledge management system (KMS) has been considered a central part of the KM projects. It is believed that a KMS which breaks down barriers by making information available at all levels and across organizational boundaries helps to enhance organizational effectiveness. As increasing organizations expended an enormous amount of time and money on these 
KM initiatives, some industry data suggested a 70-percent failure rate of KM related technology implementations and related applications (Darrell et al., 2002). This necessitates an understanding of the factors facilitating the KMS success.

Considerable KMS studies have been conducted during the last decade. King and Marks (2008) compared the effects of supervisory control and organizational support on the frequency and effort of individuals in contributing their personally held valuable knowledge to a "best practices-lessons learned, repository-based" knowledge management system (KMS). Jennex and Olfman (2005), Wu and Wang (2006) and Clay et al. (2005) used DeLone and McLean's (2003) IS Success Model as the theoretical guidance for a KMS success model. Their studies testified knowledge quality, system quality and service quality as important parts of KMS success.

Considerable KMS studies have been conducted during the last decade. King and Marks (2008) compared the effects of supervisory control and organizational support on the frequency and effort of individuals in contributing their personally held valuable knowledge to a "best practices-lessons learned, repository-based" knowledge management system (KMS). Jennex and Olfman (2005), Wu and Wang (2006) and Clay et al. (2005) used DeLone and McLean's (2003) IS Success Model as the theoretical guidance for a KMS success model. Their studies testified knowledge quality, system quality and service quality as important parts of KMS success.

Alavi and Leidner (2001) suggested that KMS research and development should preserve and build upon the significant literature that exists in different but related fields. This inspires the current study to examine the preconditions of KMS success by incorporating the perspectives of IS management, strategic management and knowledge management into an integrated model. Social capital theory (SCT) and resource-based view (RBV) are presently the dominant theoretical perspectives in strategic management literature. SCT holds that networks of relationships constitute a valuable resource for the conduct of social affairs. Researchers have found that social capital plays a critical role in the exchange and combination of intellectual capital (Nahapiet \& Ghoshal, 1998; Wasko \& Faraj, 2005; Wu \& Tsai, 2005), knowledge acquisition and exploitation (YliRenko et al., 2001), and firm survival (Fischer \& Pollock, 2004). Some of the important elements that have been addressed in the literature of knowledge sharing are trust, shared vision and social interaction ties. They have been considered as important variables encouraging knowledge sharing, which is required during the implementation of KMS as information technology (IT) staff and business experts need to identify valuable knowledge and correct business process to be codified in the KMS.

On the other hand, resource-based view focuses on costly-to-copy attributes of a firm which are seen as the fundamental drivers of performance (Conner, 1991; Bharadwaj, 2000). Researchers have adopted the perspective of RBV in linking IT to the success of knowledge management (Gold et al., 2001; Khalifa \& Liu, 2003; Lee \& Choi, 2003) and to firm performance (Bharadwaj, 2000; Tippins \& Sohi, 2003; Li et al., 2006). Given that IT has become the backbone of organizational competitiveness (Ahuja \& Thatcher, 2005), organizations' capability in utilizing IT to explore and exploit valuable knowledge may determine the extent to which such competitiveness may be sustained. An organization's IT training program to help business experts enhance job performance through KMS use, the proficiency level of IT staff, IT planning effectiveness, and IT staff's experience in system design and maintenance are therefore considered important IT capability to build and maintain high-quality KMS.

Although social capital and IT capabilities are important organizational resources, only a limited number of studies have explored how these two categories of 
resources can jointly facilitate the KMS success. The purpose of this paper is thus to incorporate KMS success model, social capital theory and resource-based view of IT in a theoretical model to identify the preconditions of the KMS success.

\section{Literature Review and Research Model}

The literatures of IS success, knowledge management, and strategic management were reviewed to develop the research model. This section elaborates on the theoretical background from which the hypotheses are derived. The research model is depicted in Figure 1.

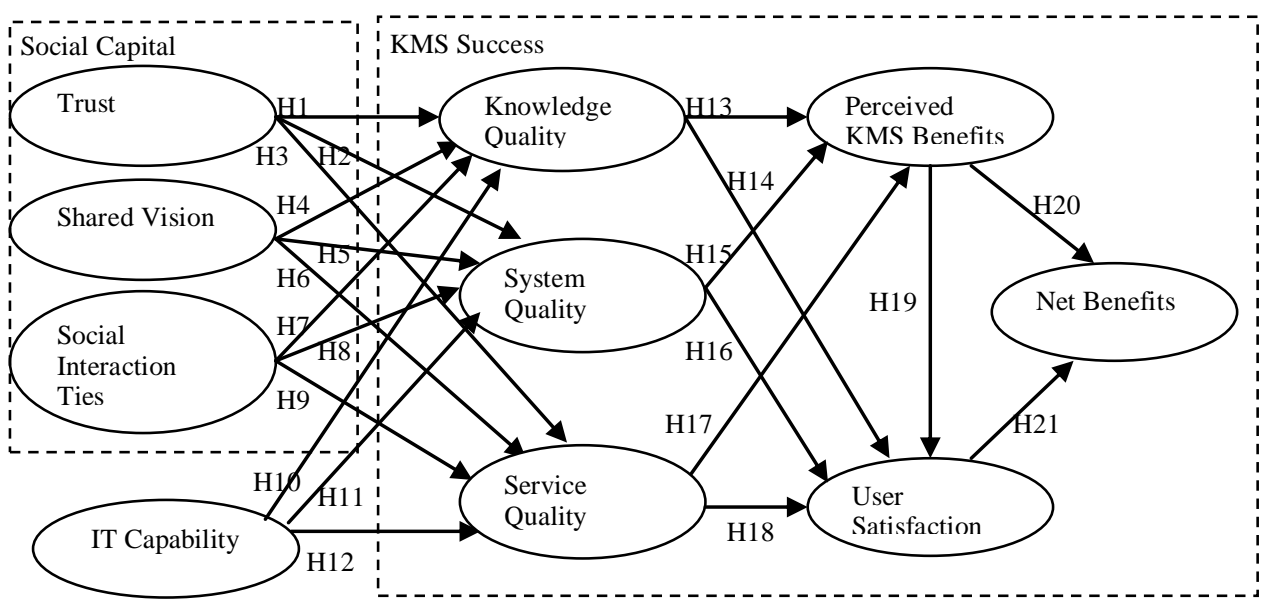

Figure 1 Research model

\subsection{Social capital}

Social capital is "the sum of the actual and potential resources embedded within, available through, and derived from the network of relationships possessed by an individual or social unit." (Nahapiet \& Ghoshal, 1998) Although it is a composite variable including several dimensions, this study focuses on the three dimensions that are widely discussed in the literature of social capital.

\subsubsection{Trust}

Trust is an implicit set of beliefs that the other party will refrain from opportunistic behaviour and will not take advantage of the situation (Hosmer, 1995). It has been recognized as an important antecedent of IS group performance (Nelson \& Cooprider, 1996), intellectual capital exchange (Nahapiet \& Ghoshal, 1998; Adler, 2001), organizational value creation (Tsai \& Ghoshal, 1998), and online knowledge contribution (Kankanhalli et al., 2005).

The goal of most KMS is characterized as "getting the right information to the right person at the right time." Therefore, it is expected that knowledge can be reused by storing all relevant knowledge, including tacit knowledge, in computerized databases, 
software programs, and, institutionalized rules and practices (Malhotra, 2003). The KMS application portfolios should be consistent with business processes, and functions in proper and reliable manner. Moreover, the IT staffs, line managers, and business experts must provide adequate support to diminish the negative feelings that users may experience in the implementation stage. These tasks for maintaining a high-quality KMS involves knowledge sharing which requires the presence of trust on co-workers' ability, reciprocal faith and truthfulness in dealing with one another (Kankanhalli et al., 2005). Therefore, the following relationships are expected to hold true:

H1: Trust is positively associated with the knowledge quality.

$\mathrm{H} 2$ : Trust is positively associated with the system quality.

H3: Trust is positively associated with the service quality.

\subsubsection{Shared vision}

Senge (1994) pointed out that a shared vision describes an image that people carry in their hearts as well as in their heads. It has the force to connect and commit individuals one to another and to the new future they are bound to create. The shared vision must reflect the concerns and interests of all organization members. A vision that permeates the organization can provide people with a needed sense of purpose that transcends everyday activities (Leonard, 1995). Tsai and Ghoshal (1998) noted that a shared vision embodies the collective goals and aspirations of the members of a unit. Organization members who share a vision will be more likely to become partners sharing or exchanging their resources (Tsai \& Ghoshal, 1998).

The purpose of using a KMS is to break down barriers by making information available at all levels and across organizational boundaries. Before implementing the KMS, its intended purpose and goals must be understood by organization members. Explicitly stated organizational vision can help enhance the quality of KMS in the way that it makes organization members understand the importance of knowledge to corporate success, and realize their responsibilities for the KMS success. Employees bearing the collective goal in mind are more likely to cooperate in the KMS project. Therefore, the following relationships are expected to hold true:

H4: Shared vision is positively associated with the knowledge quality.

H5: Shared vision is positively associated with the system quality.

H6: Shared vision is positively associated with the service quality.

\subsubsection{Social interaction ties}

Social interaction ties can be considered as a bond between two people based on one or more relations they maintain in a social network (Haythornthwaite, 1998). Prior studies found that social interactions help to create social interaction ties among members in a network, which are important predictors of collective action (Burt, 1992; Putnam, 1995; Wasko \& Faraj, 2005). Such ties tend to develop between individuals with same interest and similar resources rather than between individuals who are dissimilar (Johnson, 2004).

Some researchers have explored the roles of social interaction tie in individuals' knowledge sharing. For example, Burt and Ronchi (2007) ran a field experiment in which hundreds of executives were educated in the network structure of social capital, and observed unobtrusively after the training. The sample subjects' subsequent performance improvements in being able to identify and effectively act on strategic opportunities were substantial. Tsai and Ghoshal's (1998) empirical study demonstrated that the 
interpersonal social interaction tie has positive effect on the resource exchange. While developing and implementing a KMS, technical experts need the access to users' business process knowledge and the users, in turn, need the access to technical knowledge (e.g. user interface, system functions). The IT staff, line managers and business experts can provide timely support for users if their needs can be clearly expressed through the communications. Therefore, the following relationships are expected to hold true:

H7: Social interaction ties among knowledge workers are positively associated with the knowledge quality.

H8: Social interaction ties among knowledge workers are positively associated with the system quality.

H9: Social interaction ties among knowledge workers are positively associated with the service quality.

\subsection{Information technology capability}

The RBV literature points out that firms could obtain sustainable competitive advantage on the basis of "unique" corporate resources that are valuable, rare, difficult to imitate, and non-substitutable by other resources (Barney, 1991; Conner, 1991). Researchers and practitioners have addressed a variety of IT-related variables. For example, Li et al. (2006) and Tippins and Sohi (2003) classified IT capability into three dimensions: IT knowledge, IT operations and IT objects. This study adopts Wixom and Watson's (2001) idea and incorporates human IT resources in the current research model for the following reasons. (1) People are important when implementing a system and can directly affect its success or failure. (2) The skills of the KMS development team have a major influence on the outcomes of the project. (3) Only a competent team can identify the requirements of complex projects. Therefore, a highly skilled project team should be much better equipped to manage the project of KMS (Wixom \& Watson, 2001).

Human IT resources include technical IT skills and the managerial IT skills. IT skills concerns with the skills such as programming, systems analysis and design, and competencies in emerging technologies. Managerial IT skills include abilities such as the effective management of IS functions, coordination and interaction with user community, and project management and leadership skills (Bharadwaj, 2000). According to RBV, firms with strong human IT resources are able to integrate the IT and business planning processes more effectively, develop reliable and cost effective applications that support the business needs of the firm, communicate with business units efficiently, and anticipate future business needs of the firm and innovate valuable new product features before competitors (Bharadwaj, 2000, pp.173). Therefore, the following relationships are expected to hold true:

H10: IT capability is positively associated with the knowledge quality.

H11: IT capability is positively associated with the system quality.

H12: IT capability is positively associated with the service quality.

\subsection{Knowledge management system success}

Knowledge management systems (KMS) are systems designed to manage organizational knowledge (Alavi \& Leidner, 2001). Many researchers (e.g., Clay et al., 2005; Jennex \& Olfman, 2005; Wu \& Wang, 2006) have used DeLone and McLean's (D\&M) IS Success Model (2003) as underlying framework for the KMS success model. D\&M's model holds that the six variables-information quality, system quality, service quality, perceived 
usefulness, user satisfaction and net benefits- jointly constitute an integrated view of IS success. In the KMS context, knowledge quality substitutes for information quality and refers to the quality of the knowledge/information delivered by the KMS.

System quality is the performance of a KMS in terms of the consistency of the user interface, ease of use, response rates in interactive systems, and the accuracy of the codified business processes. A KMS with high system quality may help diminish users' negative mood such as impatience or pettishness while using the system. Service quality means how well subject matter experts and KMS managers support the KMS (Jennex \& Olfman, 2005). Many researchers found that top management support is a very critical factor in ensuring IS success implementation (Masrek et al., 2007). For instance, Bajwa et al. (1998) found that high levels of top management support indirectly influence the success of executive information systems by creating a supportive context for the IS organization.

Some scholars suggested that perceived KMS benefit can substitute for perceived usefulness in the KMS context. The new dimension not only captures IS effectiveness but also retains the concept of the degree to which a person believes that use of the system enhances his/her job performance (Wu \& Wang, 2006). User satisfaction is an affective state representing an emotional reaction to the KMS use experience, and net benefits encompass consequent enhancement of individual effectiveness and overall organizational effectiveness. Finally, Jennex and Olfman (2005) indicated that perceived KMS benefit is good for predicting continued KMS use when use of the KMS is voluntary.

Continued use has been an important variable measuring IS success in the literature of Expectation Confirmation Theory (ECT). Bhattacherjee (2001) suggested that the eventual success of IS depends on its continued use rather than first-time use. In most of the organizational KMS projects, employees initially use the KMS nonvoluntarily because the management enforces the policy. After a period of use, however, employees' perceived benefits of KMS use may become a motivation for voluntary continued-use. Hence, this study follows Wu and Wang (2006) and defines the net benefits as employees' continued use of KMS for performing their jobs.

The relationships between the aforementioned six variables have been extensively validated by prior research. This study will empirically investigate whether such relationships hold true when the influences of preconditions are taken into consideration.

H13: Knowledge quality is positively associated with perceived KMS benefit.

H14: Knowledge quality is positively associated with user satisfaction.

H15: System quality is positively associated with perceived KMS benefit.

H16: System quality is positively associated with user satisfaction.

H17: Service quality is positively associated with perceived KMS benefit.

H18: Service quality is positively associated with user satisfaction.

H19: Perceived KMS benefit is positively associated with user satisfaction.

H20: Perceived KMS benefit is positively associated with net benefit.

$\mathrm{H} 21$ : User satisfaction is positively associated with net benefit. 


\section{Data Collection}

\subsection{Procedure}

A pretest of the questionnaire was conducted using 5 experts in the IS area to assess wording clarity, question item sequence adequacy, and task relevance. Moreover, a pilot study involving 35 part-time master students in various fields was conducted. Respondents were asked to provide comments on the questionnaire content and structure.

The two-phase data used to test the proposed model was collected from the companies in Taiwan. In August 2006, the first phase survey questionnaires were mailed to middle managers in 400 business organizations of three industry types: manufacturing, service, and financial business (banking, finance, insurance). The reason that questionnaires were mailed to middle managers is that they interacted intensively with IT experts, top managers, and frontline employees. Thus, they were able to provide commentary of their organization's social capital, IT capability, KMS quality (knowledge, system, service), and the consequences of KMS use.

A small gift and a cover letter explaining the purpose of the survey were mailed along with each questionnaire. These questionnaires asked questions for the measurement of social capital, IT capability, and the stage of the KMS implementation in each organization (none, pre-implementation, post-implementation). All respondents were guaranteed confidentiality of individual responses. 301 responses were received and the 215 responses from firms that were in the pre-implementation stage were kept for the follow-up survey.

In April 2007, the second phase survey questionnaires were mailed to the 215 middle managers. This survey aimed to find out the current stage of the KMS implementation in each organization and investigate the KMS quality, users' perceived KMS benefits, satisfaction and the net benefits. 208 responses were collected and used for the data analysis. Among the responses, $51 \%$ were in service industry, $34 \%$ were in financing industry, and $15 \%$ were in manufacturing industry.

\subsection{Construct measurement}

All items were developed based on items from existing instruments or the definitions provided in the literatures of IS, strategic management, and knowledge management. Items were measured based on a seven-point Likert scale ranging from (1) "strongly disagree" or "extremely poor" to (7) "strongly agree" or "extremely good".

Social capital was measured using questions that captured the levels of mutual trust, social interaction ties among knowledge workers, and how well the organizational objectives were understood by employees. Measurement items were adapted from Gold et al. (2001), Lee and Choi (2003). Information technology capability was measured using four items that were self-developed based on the definition provided in the literature (Bharadwaj, 2000). These items assessed the proficiency level of IT experts who involved in the KMS implementation, and IT-related training program for users and line-managers to advance their IT skills.

Knowledge quality was operationalized as the relevance, timeliness, and completeness of information/knowledge provided by the KMS. Convenience of access, ease of use, response time and the correctness of codified business procedure have been shown to be important dimensions of system quality (McKinney et al., 2002; Jennex \& Olfman, 2005). Service quality was measured using four items derived from Jennex and 
Olfman (2005). Perceived KMS benefit was measured using items adapted from Jennex and Olfman (2005) and Wu and Wang (2006), while satisfaction was measured by items adapted from prior work by Bhattacherjee and Premkumar (2004), Lee and Choi (2003) and Wu and Wang (2006). Finally, the items for measuring net benefits were derived from Lee and Choi (2003) and Wu and Wang (2006).

\section{$4 \quad$ Data Analysis}

\subsection{Construct reliability and validity}

Construct reliability and validity for the ten measurement scales were evaluated via confirmatory factor analysis (CFA) approach using LISREL program. Items that demonstrate poor reliabilities were dropped and the model was then reestimated. For the current CFA model, $\chi 2 / \mathrm{df}$ was $1.72(\chi 2=939.24 ; \mathrm{df}=543)$, NFI was 0.85 , NNFI was 0.91 , CFI was 0.93, GFI was 0.80, and SRMSR was 0.04, suggesting adequate model fit.

Construct reliability was examined using the Cronbach's alpha values. As shown in Table 1, all of these values were greater than 0.76 , well above the commonly acceptance levels of 0.70 (Gefen et al., 2000). Convergent validity was evaluated for the measurement scales using the three criteria suggested by Fornell and Larcker (1981): (1) all indicator loadings $(\lambda)$ should be significant and exceed $0.7,(2)$ construct reliabilities should exceed 0.8 , and (3) average variance extracted (AVE) by each construct should exceed the variance due to measurement error for that construct (i.e., each AVE should exceed 0.50 ). Only eight of the thirty-eight $\lambda$ and three of the ten construct reliability values were slightly below the recommended threshold. AVEs ranged from 0.55 to 0.96 .

Finally, discriminant validity of the resulting scales was assessed using the guideline suggested by Fornell and Larcker (1981): the AVE for each construct should exceed the squared correlation between that and any other construct. The AVEs and the squared correlations among constructs listed in Table 1 signify acceptable discriminant validity of the measurement scales.

Table 1: Discriminant Validity for the Constructs

\begin{tabular}{|c|c|c|c|c|c|c|c|c|c|c|c|}
\hline \multirow{2}{*}{ Construct } & \multicolumn{2}{|c|}{ CR } & \multicolumn{7}{|c|}{ AVE and squared correlations } \\
\cline { 2 - 11 } & & TR & SV & SI & IT & KQ & SQ & SEQ & PB & SAT & NB \\
\hline TR & .76 .68 & & & & & & & & & \\
\hline SV & .77 & $.42(* *)$ & .55 & & & & & & & & \\
\hline SI & .80 & $.42(* *)$ & $.44(* *)$ & .68 & & & & & & & \\
\hline IT & .76 & $.41(* *)$ & $.52(* *)$ & $.43(* *)$ & .70 & & & & & & \\
\hline KQ & .87 & $.44(* *)$ & $.47(* *)$ & $.57(* *)$ & $.42(* *)$ & .80 & & & & & \\
\hline SQ & .82 & $.36(* *)$ & $.50(* *)$ & $.34(* *)$ & $.56(* *)$ & $.50(* *)$ & 73 & & & & \\
\hline SEQ & .88 & $.38(* *)$ & $.55(* *)$ & $.45(* *)$ & $.40(* *)$ & $.65(* *)$ & $.57(* *)$ & .83 & & & \\
\hline PB & .88 & $.48(* *)$ & $.42(* *)$ & $.40(* *)$ & $.42(* *)$ & $.53(* *)$ & $.41(* *)$ & $.47(* *)$ & .81 & & \\
\hline SAT & .95 & $.36(* *)$ & $.41(* *)$ & $.35(* *)$ & $.50(* *)$ & $.55(* *)$ & $.54(* *)$ & $.60(* *)$ & $.57(* *)$ & .96 & \\
\hline
\end{tabular}




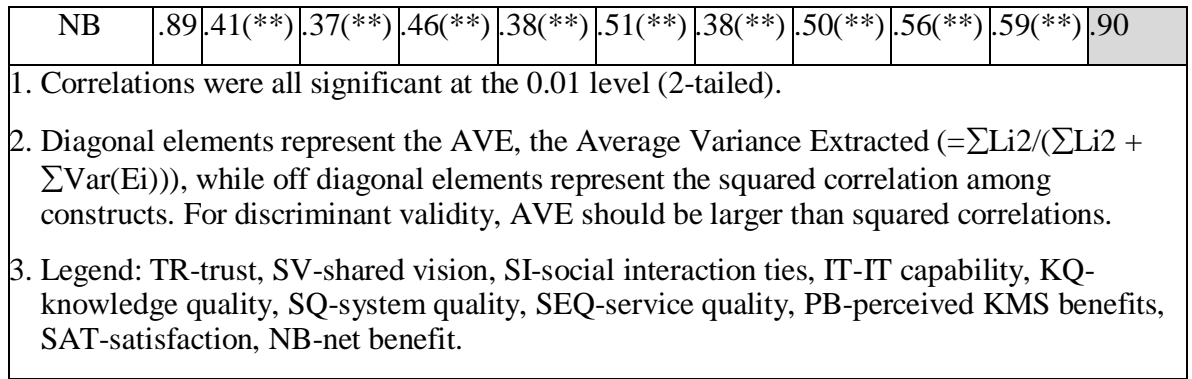

\section{2. $\quad$ Structural model testing}

The structural equation modeling (SEM) approach is applied using LISREL 8.50 to examine the overall fit of the model, the explanatory power of research model, and the relative strengths of the individual causal path. For models with good fit, $\chi 2$ to degrees of freedom ratio should be less than 5; NFI, NNFI, CFI, GFI and AGFI should exceed 0.9; SRMSR should be less than 0.1 . These indices in this study all met the criteria except the AGFI which had a value slightly below the recommended threshold (GFI $=0.95$; NFI= 0.97; NNFI= 0.92; $\mathrm{CFI}=0.98, \mathrm{SRMSR}=0.031 ; \chi 2=56.55$; degrees of freedom ratio $=13$; AGFI $=0.83)$. The overall results suggested that the research model provided a reasonably good fit to the data.

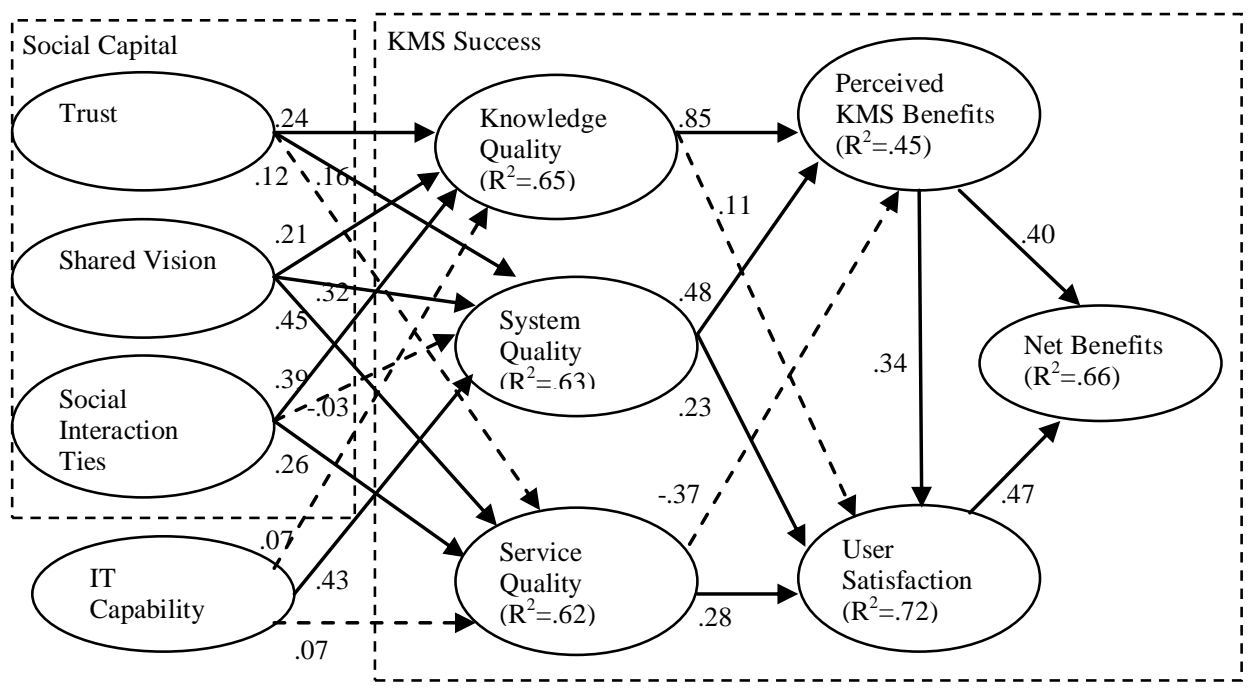

Figure 2 SEM analysis result

The strength of each hypothesized relationship in the research model and variance explained (R2 value) by these paths were summarized in Figure 2. Trust had positive and significant effect on the KMS quality except the service quality. Shared vision had significant effect on three types of KMS quality. Social interaction ties significantly influenced the KMS quality except system quality, whereas IT capability significantly influenced system quality only. These four independent variables jointly explained $65 \%, 63 \%$, and $62 \%$ of knowledge quality variance, system quality variance and service quality variance, respectively. Knowledge quality significantly influenced 
perceived KMS benefits yet had a non-significant relationship with satisfaction. System quality and service quality both had significant and positive influences on satisfaction. However, service quality had a negative relationship with perceived KMS benefits. These three types of KMS quality jointly explained $45 \%$ and $72 \%$ of perceived benefits variance and satisfaction variance, respectively. Finally, perceived KMS benefits and satisfaction both had significant and positive effects on net benefits and jointly explained $66 \%$ of its variance. In sum, the hypotheses H3, H8, H10, H12, H14 and H17 were not supported by the result of data analysis whereas the rest of hypotheses were supported.

\section{Discussion and Limitations}

\subsection{Discussion}

Several findings of this study are worth noting. First of all, trust is shown to be significantly associated with knowledge quality and system quality. Yet, against the prior expectation, its association with service quality is non-significant. The model of responsibility assignment (Brickman et al., 1982) holds that managers are blamed when they are perceived to have been negligent in carrying out duties or obligations of their organizational or occupational role. Hence, one possible explanation of this finding is that in the project of KMS implementation, IT staff, line managers and subject matter experts are prone to provide necessary supports to avoid being blamed for hindering the project, even if there is a lack of trust. Future investigations on the comparative strength of these social capital attributes in affecting the quality of other information systems will be useful for generalizing this finding in various IS contexts.

Secondly, shared vision is shown to be positively and significantly associated with the three types of KMS quality. This finding is consistent with the concept of social capital theory which holds that when organization members share common interests, they are more likely to cooperate with other knowledge workers to accomplish the collective goal. Moreover, the influence of shared vision on the service quality is relatively larger than its influence on knowledge quality and service quality. This indicates that explicitly stated organizational goals, rules and common interests are very useful for encouraging business managers and subject matter experts to provide supports for the project.

Thirdly, social interaction ties appear to exert stronger influence on knowledge quality and service quality than trust does. Many scholars suggested that trust is developed through repeated interactions with time or through social network that people established (Ring \& Van de Ven, 1992). Further study is thus suggested to investigate whether social interaction ties among knowledge workers help extend the scope and level of mutual trust among organization members in the KMS context.

Fourthly, IT capability is significantly associated with system quality rather than knowledge quality and service quality, and it exerts the strongest influence on system quality among the four independent variables. Some plausible reasons are that although IT staffs' technical skill and business users' IT related training are useful for developing a KMS with appropriate application portfolios, these well-qualified IT staffs may still lack the ability in judging the accuracy of the information they collect from business users; although an experienced system analyst may be able to help line managers and subject matter experts provide adequate support, they have no control on how and to what extent this (providing adequate support) will be done. Some challenges for executives will be to set up regulation rules as well as rewarding mechanism to encourage line managers to provide support. A research avenue extended from the current result will be to investigate 
whether reorganization helps to improve the communications between IT staff and business users.

Fifthly, no significant association between knowledge quality and satisfaction is observed, whereas knowledge quality has a very strong effect on the perception of KMS benefits. This is not consistent with some empirical findings of KMS studies. This leads to a review of the four parts of the sample data: knowledge quality, satisfaction, perceived KMS benefits and the sample demographics. Eleven responses from five companies gave high scores (above 4) for items measuring knowledge quality, but gave low scores (2 3) for items measuring satisfaction. These companies had implemented their knowledge management systems less than one month prior to the second survey. This provides a possible explanation that users who do not have pleasant experience in using the newly-implemented KMS can still benefit by the timely updated and integrated knowledge which they might not be able to acquire before.

Sixthly, consistent with prior studies, system quality is shown to be positively and significantly associated with perceived KMS benefits and satisfaction. However, the significant yet negative relationship between service quality and perceived KMS benefits does not prove previous conjecture. Although the relationships between service quality and intention to use/use/perceived usefulness have been shown to be positive and significant in the literatures of eGovernment system success (Wang \& Liao, 2007) and CRM system success (Roh et al., 2005), these studies focus on 'system support' rather than 'management support' in measuring the service quality. Kettinger and Lee (2005) suggest that IS customer service expectations are characterized by a range of levels including desired service, adequate service and perceived service quality levels. The level of expectation or desired support for KMS use, and the perception of adequate service may change with time as users gain experience of KMS use. Most sample subjects in this study have used the KMS over one month. Over management support may become management intervention when individuals have become experienced KMS users. Further empirical studies are suggested to prove the generalizability of this finding.

Finally, the significant and positive relationship between perceived benefits and satisfaction supports the research hypothesis and other empirical findings by Bhattacherjee (2001) and Wu and Wang (2006). Moreover, perceived KMS benefits and satisfaction both have significant effects on net benefits. These results lend support for previous findings of KMS studies (e.g., Jennex \& Olfman, 2005; Wu \& Wang, 2006) which suggest that perceived KMS benefits and satisfaction are good predictors of net benefits.

\subsection{Limitations of the study}

Although this research reveals some preconditions of the KMS success, it suffers from several limitations. First, this study focused on social capital and IT capability to examine the antecedents of KMS success. Some variables addressed in prior KM research such as culture, commitments, or motivations are not discussed in this study. Moreover, although this study adopted the longitudinal research methodology, the timeline of the survey is relatively short in terms of the long-term development of organizational social capital and IT capability. Bhattacherjee and Premkumar (2004) suggested that IS success relies on initial use and continued use. In the two stages of IT usage, users' cognitive beliefs and attitude may change with time as users gain first-hand experience with IT usage behaviour. Since the development of social capital and IT capability is an ongoing 
phenomenon within organizations, a future longitudinal study with a longer postimplementation period may help to reveal more findings.

\section{Conclusions}

Developing a Web-based knowledge environment to enhance customer satisfaction or sustain competitive advantage has become an emergent trend in Internet economy era. Digital firms, no matter conglomerates that have a large global base of employees and clients, or small companies that have globally dispersed employees and business partners, face a number of problems in managing knowledge. Building and maintaining successful knowledge management systems to cope with these problems thus have become a critical part of the KM strategy. This study brings a contribution to KMS literature by empirically validating some social capital attributes and IT capability as the preconditions of KMS success. The current findings will be useful for managers to effectively identify and adopt the key strategies for improving particular type of KMS quality to achieve organizational goals.

\section{Acknowledgements}

I would like to express special thanks to editors for their thoughtful comments and constructive suggestions. This work is supported by National Science Council, Taiwan under grants NSC 96-2520-S-231 -001 and NSC 97-2410-H-231 -019.

\section{References}

1 Adler, P.S. (2001). Market, hierarchy and trust: the knowledge economy and the future of capitalism. Organization Science, 12(2), 215-234.

2 Ahuja, M.K., \& Thatcher, J.B. (2005). Moving beyond intentions and toward the theory of trying: effects of work environment and gender on post-adoption information technology use. MIS Quarterly, 29(3), 427-459.

3 Alavi, M., \& Leidner, D.E. (2001). Review: knowledge management and knowledge management systems: conceptual foundations and research issues. MIS Quarterly, 25(1), 107-136.

4 Bajwa, D.S., Rai, A., \& Brennan, I. (1998). Key antecedents of executive information system success: a path analytic approach. Decision Support Systems, 22(1), 31-43.

5 Barney, J.B. (1991). Firm resources and sustained competitive advantage. Journal of Management, 17, 99-120.

6 Bharadwaj, A.S. (2000). A resource-based perspective on information technology capability and firm performance: an empirical investigation. MIS Quarterly, 24(1), 169-196.

7 Bhattacherjee, A. (2001). Understanding information systems continuance: an expectation-confirmation model. MIS Quarterly, 25(3), 351-370.

8 Bhattacherjee, A., \& Premkumar, G. (2004). Understanding changes in belief and attitude toward information technology usage: a theoretical model and longitudinal test. MIS Quarterly, 28(2), 229-254. 
9 Brickman, P., Rabinowitz, V.C., Karuza, J., Coates, Jr., D., Cohn, E., \& Kidder, L. (1982). Models of helping and coping. American Psychologist, 37(4), 368-384.

10 Burt, R.S. (1992). Structural Holes: The Social Structure of Competition. Cambridge, MA: Harvard University Press.

11 Burt, R.S., \& Ronchi, D. (2007). Teaching executives to see social capital: results from a field experiment. Social Science Research, 36(3), 1156-1183.

12 Butler, T., Feller, J., Pope, A., Emerson, B., Murphy, C. (in press). Designing a core IT artefact for knowledge management systems using participatory action research in a government and a non-government organisation. Journal of Strategic Information Systems.

13 Chua, A., Lam, W. (2005). Why KM project fail: a multi-case analysis. Journal of Knowledge Management, 9(3), 6-17.

14 Clay, P.F., Dennis, A.R., \& Ko, D.G. (2005). Factors affecting the loyal use of knowledge management systems. Proceedings of the 38th Hawaii International Conference on System Sciences (pp. 251c-251c).

15 Conner, K.R. (1991). A historical comparison of the resource-based theory and five schools of thought within industrial organization economics: do I have a new theory of the firm. Journal of Management, 17(1), 121-54.

16 Darrell, R., Reichheld, F.F., \& Schefter, P. (2002). Avoid the four perils of CRM. Harvard Business Review, 101-109.

17 Davenport, T.H., \& Prusak, L. (1998). Working Knowledge, Harvard Business School Press, Boston, MA.

18 DeLone, W.H., \& McLean, E.R. (2003). The DeLone and McLean model of information systems success: a ten-year update. Journal of Management Information Systems, 19(4), 9-30.

19 Fischer, H.M., \& Pollock, T.G. (2004). Effects of social capital and power on surviving transformational change: the case of initial public offerings. Academy of Management Journal, 47(4), 463-481.

20 Fornell, C., \& Larcker, D.F. (1981). Evaluating structural equation models with unobservable variables and measurement error. Journal of Marketing Research, 18(1), 39-50.

21 Gefen, D., Straub, D.W., \& Boudreau, M.C. (2000). Structural equation modeling and regression: guidelines for research practice. Communication of the Association for Information Systems, 4(7), 1-70.

22 Gold, A.H., Malhotra, A., \& Segars, A.H. (2001). Knowledge management: an organizational capabilities perspective. Journal of Management Information Systems, 18(1), 185-214.

23 Haythornthwaite, C. (1998). A social network study of the growth of community among distance learners. Information Research, 4(1). Retrieved April 27, 2008, from http://informationr.net/ir/4-1/infres41.html.

24 Hosmer, L.T. (1995). Trust: the connecting link between organizational theory and philosophical ethics. Academy of Management Review, 20(2), 379-403.

25 Jennex, M.E., \& Olfman, L. (2005). Assessing knowledge management success. International Journal of Knowledge Management, 1(2), 33-49.

26 Johnson, C.A. (2004). Choosing people: the role of social capital in information seeking behaviour. Information Research, 10(1). Retrieved March 15, 2008, from http://informationr.net/ir/10-1/infres101.html. 
27 Kankanhalli, A., Tan, B.C.Y., \& Wei, K.K. (2005). Contributing knowledge to electronic knowledge repositories: an empirical investigation. MIS Quarterly, 29(1), 113-143.

28 Kettinger, W.J., \& Lee, C.C. (2005). Zones of tolerance: alternative scales for measuring information systems service quality. MIS Quarterly, 29(4), 607-623.

29 Khalifa, M., \& Liu, V. (2003). Determinants of successful knowledge management programs. Electronic Journal of Knowledge Management, 1(2), 103-112.

30 King, W.R., Marks, P.V. (2008). Motivating knowledge sharing through a knowledge management system. Omega, 36(1), 131-146.

31 Lee, H., \& Choi, B. (2003). Knowledge management enablers, processes, and organizational performance: an integrative view and empirical examination. Journal of Management Information Systems, 20(1), 179-228.

32 Leonard, D. (1995). Wellsprings of Knowledge: Building and Sustaining the Source of Innovation. Boston: Harvard Business School Press.

33 Li, E.Y., Chen, J.S., \& Huang, Y.H. (2006). A framework for investigating the impact of IT capability and organizational capability on firm performance in the late industrializing context. International Journal of Technology Management, 36(1/2/3), 209-229.

34 Malhotra, Y. (2003) Why Knowledge Management Systems Fail? Enablers and Constraints of Knowledge Management in Human Enterprises. Handbook on Knowledge Management. Springer-Berlag, Heidelberg in the "International Handbook on Information Systems" Series.

35 Masrek, M.N., Karim, N.S.A., \& Hussein, R. (2007). Investigating corporate intranet effectiveness: a conceptual framework. Information Management \& Computer Security, 15(3), 168-183.

36 McKinney, V., Yoon, K., \& Zahedi, F.M. (2002). The measurement of webcustomer satisfaction: an expectation and disconfirmation approach. Information Systems Research, 13(3), 296-315.

37 Nahapiet, J., \& Ghoshal, S. (1998). Social capital, intellectual capital, and the organizational advantage. Academy of Management Review, 23(2), 242-266.

38 Nelson, K.M., \& Cooprider, J.G. (1996). The contribution of shared knowledge to IS group performance. MIS Quarterly, 20(4), 409-429.

39 Putnam, R.D. (1995). Bowling alone: America's declining social capital. Journal of Democracy, 6, 65-78.

40 Ring, P.S., \& van de Ven, A.H. (1992). Structuring cooperative relationships between organizations. Strategic Management Journal, 13, 483-498.

41 Robertson, S. (2002). A tale of two knowledge-sharing systems. Journal of Knowledge Management, 6(3), 295-308.

42 Roh, T.H., Ahn, C.K., \& Han, I. (2005). The priority factor model for customer relationship management system success. Expert Systems with Applications, 28(4), 641-654.

43 Senge, P. (1994). The Fifth Discipline Fieldbook: Strategies for Building a Learning Organization. New York: Currency Doubleday.

44 Tippins, M.J., \& Sohi, R.S. (2003). IT competency and firm performance: is organizational learning a missing link? Strategic Management Journal, 24(8), 745761 . 
45 Tsai, W., \& Ghoshal, S. (1998). Social capital and value creation: the role of intrafirm networks. Academy of Management Journal, 41(4), 464-476.

46 Wang, Y.S., \& Liao, Y.W. (2008). Assessing eGovernment systems success: a validation of the DeLone and McLean model of information systems success. Government Information Quarterly, 25(4), 717-733.

47 Wasko, M.M., \& Faraj, S. (2005). Why should I share? Examining social capital and knowledge contribution in electronic networks of practice. MIS Quarterly, 29(1), 35-57.

48 Wixom, B.H., \& Watson, H.J. (2001). An empirical investigation of the factors affecting data warehousing success. MIS Quarterly, 25(1), 17-41.

$49 \mathrm{Wu}, \mathrm{W} . Y .$, \& Tsai, H.J. (2005). Impact of social capital and business operation mode on intellectual capital and knowledge management. International Journal of Technology Management, 30(1/2), 147-171.

50 Wu, J.H., \& Wang, Y.M. (2006). Measuring KMS success: a respecification of the DeLone and McLean's model. Information \& Management, 43(6), 728-739.

51 Yli-Renko, H., Autio, E., \& Sapienza, H.J. (2001). Social capital, knowledge acquisition, and knowledge exploitation in young technology-based firms. Strategic Management Journal, 22(6-7), 587-613. 